Analisis perbedaan long drive swing mechanical movement terhadap ball velocity berbasis pendekatan kinematics analysis antara skill dan unskill golf player

\title{
Difference analysis of long drive swing mechanical movement towards ball velocity based on analysis kinematics approach between skill and unskill golf player
}

\author{
Agus Rusdiana', Hadi Sartono², Dede Rohmat Nurjaya ${ }^{3}$, Angga M. \\ Syahid $^{4}$ \\ ${ }^{1}$ Department of Sports Science, Faculty of Sports and Health Education, Universitas \\ Pendidikan Indonesia, Jl. DR. Setiabudi No.229, Bandung, 40154, Indonesia \\ ${ }^{2,3,4}$ Department of Sports Coaching Education, Faculty of Sports and Health Education, \\ Universitas Pendidikan Indonesia, JI. DR. Setiabudi No.229, Bandung, 40154, Indonesia
}

Received: 23 March 2019; Revised: 29 April 2019; Accepted: 30 April 2019

doi) https://doi.org/10.29407/js unpgri.v5i1.12804

\begin{abstract}
Abstrak
Tujuan penelitian ini adalah ingin mengetahui perbedaan long drive swing mechanical movement terhadap ball velocity berbasis pendekatan kinematics analysis antara skill dan unskill golf player. Adapun Analisis kinematik terdiri dari: trunk forword tilt, club stick velocity, knee flexion, wrist hinge at the top, leading arm angle, lateral band, hip rotation dan shoulder rotation. Metode yang digunakan dalam penelitian ini adalah metode deskriptif kuantitatif, sedangkan teknik analisis data menggunakan analisis uji perbedaan rata-rata. Sampel dalam penelitian ini adalah 2 atlet professional dan 4 atlet amatir di lingkungan Universitas Pendidikan Indonesia UPI Bandung, dengan rata-rata Tinggi Badan $1.63 \pm 2.4 \mathrm{~m}$, Berat Badan $72.4 \pm 3.6 \mathrm{~kg}$ dan Usia $37.4 \pm 7.6$ tahun. Hasil penelitian ini menunjukan bahwa dari sepuluh variabel kinematika yang dianalisis terdapat empat indikator yang menunjukan hasil perbedaan signfikan pada taraf alpha 0.05 antara lain club speed at impact $(\mathrm{t}=0.007)$, lateral band after impact ball $(\mathrm{t}=0.006)$, shoulder rotation $(\mathrm{t}=0.005)$ dan flexion at elbow joint arm non dominant $(\mathrm{t}=0.003)$.
\end{abstract}

Kata kunci: golf, long drive swing, mekanika gerak, biomekanika olahraga.

\begin{abstract}
The purpose of this study was to find out the differences in swing mechanical movement long drives towards the ball velocity based on the kinematics analysis approach between skills and unskilled golf players. The kinematic variables analysis consists of trunk forword tilt, club stick velocity, knee flexion, wrist hinge at the top, leading arm angle, lateral band, hip rotation dan shoulder rotation. The method used in this research is quantitative descriptive method, while the data analysis technique uses the average difference test analysis. The sample in this study were 2 trained and 4 amateur athletes in the Indonesian Education University of UPI Bandung, with an average of height $1.63 \pm 2.4 \mathrm{~m}$, Body mass $72.4 \pm 3.6 \mathrm{~kg}$ and Age $37.4 \pm 7.6$ years. The results of this study indicate that of the ten kinematics variables analyzed there were four indicators which showed significant differences in the level of alpha 0.05 including club speed at impact ( $t$ $=0.007)$, lateral band after impact ball $(t=0.006)$, shoulder rotation $(t=0.005)$
\end{abstract}


Agus Rusdiana, Hadi Sartono, Dede Rohmat Nurjaya, dan Angga M. Syahid

Analisis perbedaan long drive swing mechanical movement terhadap ball velocity berbasis pendekatan kinematics analysis antara skill dan unskill golf player

and non dominant dominant flexion at elbow joint arm $(t=0.003)$.

Keywords: golf, long swing drive, mechanical movement, sport biomechanics.

\section{PENDAHULUAN}

Biomekanika merupakan ilmu yang mengkaji struktur dan fungsi sistem biologis ditinjau pada sistem mekanisnya (Nesbit, 2007; Ferdinands, Kersting, \& Marshall, 2013). Salah satu cabang dari ilmu biomekanik yaitu biomekanika olahraga (sport biomechanics) dimana kaidah mekanika diaplikasikan untuk menganalisis gerakan agar tercapai performa maksimum secara efesien, efektif dan mengurangi cedera selama berlatih dan pertandingan (Vena, Budney, Forest, \& Carey, 2011). Pemahaman biomekanika olahraga yang tepat dapat berimplikasi pada peningkatan performa, rehabilitasi dan pencegahan cedera selama seorang atlet melakukan latihan atau pertandingan yang pada akhirnya mampu menghasilkan suatu prestasi olahraga yang optimal (Mun, Suh, Park, \& Choi, 2015). Tujuan biomekanika dalam implementasi meningkatkan performa yaitu mengetahui konsep ilmiah dasar yang diaplikasikan dalam bentuk gerak manusia, memahami suatu bentuk atau model gerak dasar dalam olahraga sehingga mampu mengembangkannya dengan baik, mampu memahami perkembangan gerak dasar secara benar.

Biomekanika menyangkut tubuh manusia dan hampir semua tubuh makhluk hidup. Dalam biomekanika prinsip-prinsip mekanika digunakan dalam penyusunan konsep, analisis, disain dan pengembangan peralatan dan sistem keolahragaan. Sedangkan mekanika adalah salah satu cabang ilmu dari bidang ilmu fisika yang mempelajari gerakan dan perubahan bentuk suatu materi yang diakibatkan oleh gangguan mekanik yang disebut gaya. Perpaduan antara silang keilmuan dan implementasi teknologi dalam keolahragaan merupakan salah satu strategi dalam upaya meningkatkan kualitas performa atlet (Kwon, Kim, Lim, Park, \& Sung, 2015; Tinmark, Hellström, Halvorsen, \& Thorstensson, 2010; Morrison, McGrath, \& Wallace, 2018). 
Golf adalah permainan luar ruang yang dimainkan secara perorangan atau tim yang berlomba memasukkan bola ke dalam lubanglubang yang ada di lapangan dengan jumlah pukulan paling sedikit. Permainan golf bertujuan untuk memindahkan bola dari satu tempat ke tempat lainnya dengan jumlah pukulan sedikit mungkin. Pada permainan olahraga golf, hal yang terpenting adalah teknik memukul bola, ketenangan, konsentrasi yang tinggi akan mempengaruhi pukulan seseorang. Terlihatnya dalam memukul bola sangatlah mudah namun dalam kenyataannya hal ini lah yang tersulit dan teknik yang paling mendasari harus dikuasai oleh seorang atlet golf (Bourgain et al., 2018). Dalam permainan golf terdapat tiga teknik memukul bola yang harus dilakukan dengan benar agar menghasilkan pukulan yang akurat dan lebih jauh. Ketiga teknik tersebut yakni mempersiapkan sikap dasar, memegang grip dengan benar dan mengayunkan stik golf (Bourgain et al., 2018). Apabila ketiga teknik ini dilakukan dengan benar maka atlet berpeluang menghasilkan pukulan yang akurat untuk mencetak skor terbaik dan memenangkan permainan.

Dalam golf tidak hanya membutuhkan tenaga yang kuat tetapi yang lebih diperlukan yaitu ketelitian, ketepatan dan kecermatan (Sato, Kenny, \& Dale, 2013). Sebagian orang berpikir bahwa golf hanya memukul bola dengan jauh dan yang lebih jauhlah yang menang. Sebenarnya anggapan tersebut kurang tepat, ketelitian, ketepatan dan kecermatan lebih diperlukan walaupun atlet yang memiliki tenaga yang kuat lebih diuntungkan karena pada pukulan berikutnya lebih dekat ke lubang (Morrison et al., 2018). Kekuatan mungkin bukan satu-satunya unsur penting untuk bermain golf dengan baik, karena belum tentu pukulan yang jauh dapat menjamin seseorang bermain dengan baik.

Secara rangkaian mekanika gerak, teknik melakukan swing golf hampir sama dengan teknik swing dalam permainan bisbol. Hanya saja pada permainan bisbol, bola berada di ketinggian atas pinggang saat dipukul, sedangkan bola golf berada di permukaan tanah saat dipukul. Seperti halnya dalam bisbol untuk memperoleh pukulan terjauh atlet tak 
hanya mengandalkan kekuatan ayunan tangan saja tapi juga didukung dengan gerakan rotasi tubuh yang selaras dengan arah ayunan stik golf (Joyce, Burnett, Cochrane, \& Ball, 2013). Perpaduan antara momen tumbukan, gaya sentrifugal dan gerakan ayunan yang alami dapat memperoleh hasil pukulan yang lebih optimal. Untuk memperoleh kekuatan ayunan yang optimal, atlet harus mengkombinasikan kekuatan ayunan dari tangan, lengan, rotasi bahu, stik golf serta kokohnya tumpuan kaki serta gerakan ayunan seluruh tubuh yang selaras dengan arah pukulan (Langdown, Bridge, \& Li, 2012).

Hampir semua atlet golf bisa melakukan pukulan jarak jauh. Kesalahan mendasar dalam pukulan jarak jauh terjadi pada fase backswing dan downswing (Evans \& Tuttle, 2015). Teknik backswing adalah sebuah gerakan dalam permainan golf dimana stik grip akan diayunkan hingga posisinya di atas kepala. Sedangkan untuk teknik downswing adalah sebuah gerakan dalam permainan golf dimana stik grip akan diayunkan hingga posisinya berada sampai menyentuh bola. Kedua teknik ini harus benar-benar dikuasai agar pantulan bola seimbang hingga menuju sasaran yang ditentukan (Ferdinands et al., 2013).

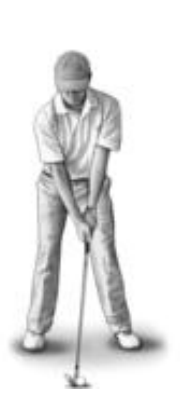

(a)

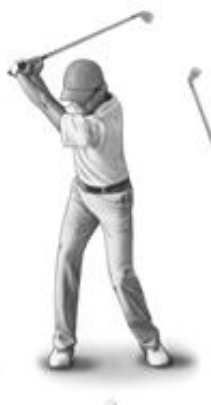

(b)

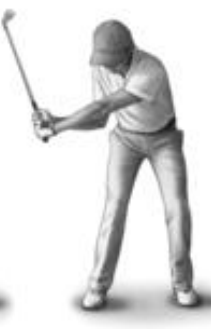

(c)

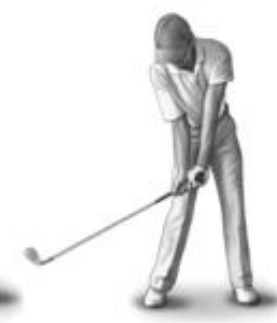

(d)

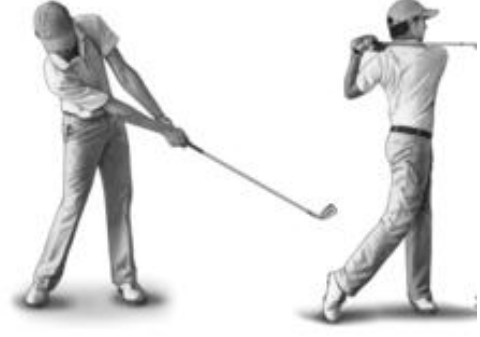

(e)

(f)

Gambar 1. Fase gerak full swing;(a-b) backswing, (b-c) transition, (c-e) downswing,(e-f) follow through

Selanjutnya kesalahan mendasar yang lainnya adalah dalam menjaga kesimbangan gerak tubuh (balance body movement). Kunci dari teori swing golf yang natural namun bertenaga adalah keseimbangan. Atlet harus mengatur posisi tubuhnya sehingga tampak kokoh demi memperoleh kesimbangan yang optimal ketika melakukan ayunan (Keogh 
\& Hume, 2012). Ketika hendak melakukan pukulan letakan posisi kaki sedikit lebih lebar daripada bahu sehingga berat badan bertumpu secara merata di kedua kaki. Tekuk lutut sedikit untuk memberi dorongan tambahan ketika melakukan ayunan. Seperti pendulum, posisi awal sebelum downswing menempatkan titik berat berada di tengah antara kedua kaki. Kemudian pada saat terjadi impact ball perpindahan berat badan $75 \%$ terjadi pada kaki depan dan $25 \%$ terjadi di kaki belakang. Karena distribusi berat badan ini seimbang dan kuat maka terjadinya goyangan saat melakukan swing juga minimal (Meister et al., 2016).

Berdasarkan uraian latar belakang di atas, penelitian ini akan lebih fokus terhadap kajian mendasar analisis perbedaan long drive swing mechanical movement terhadap kecepatan bola yang berbasis pendekatan kinematics variable analysis antara skill dan unskill golf player.

\section{METODE}

Tempat pengambilan data dilaksanakan di Golf Driving Range Fakultas Pendidikan Olahraga dan Kesehatan, Universitas Pendidikan Indonesia (UPI) Bandung. Sedangkan sampel dalam penelitian ini adalah 2 atlet pro dan 4 atlet amatir di lingkungan Universitas Pendidikan Indonesia Bandung dengan rata-rata Tinggi Badan $1.63 \pm 2.4 \mathrm{~m}$, Berat Badan $72.4 \pm 3.6 \mathrm{~kg}$ dan Usia $37.4 \pm 7.6$ tahun . 
Agus Rusdiana, Hadi Sartono, Dede Rohmat Nurjaya, dan Angga M. Syahid

Analisis perbedaan long drive swing mechanical movement terhadap ball velocity berbasis pendekatan kinematics analysis antara skill dan unskill golf player
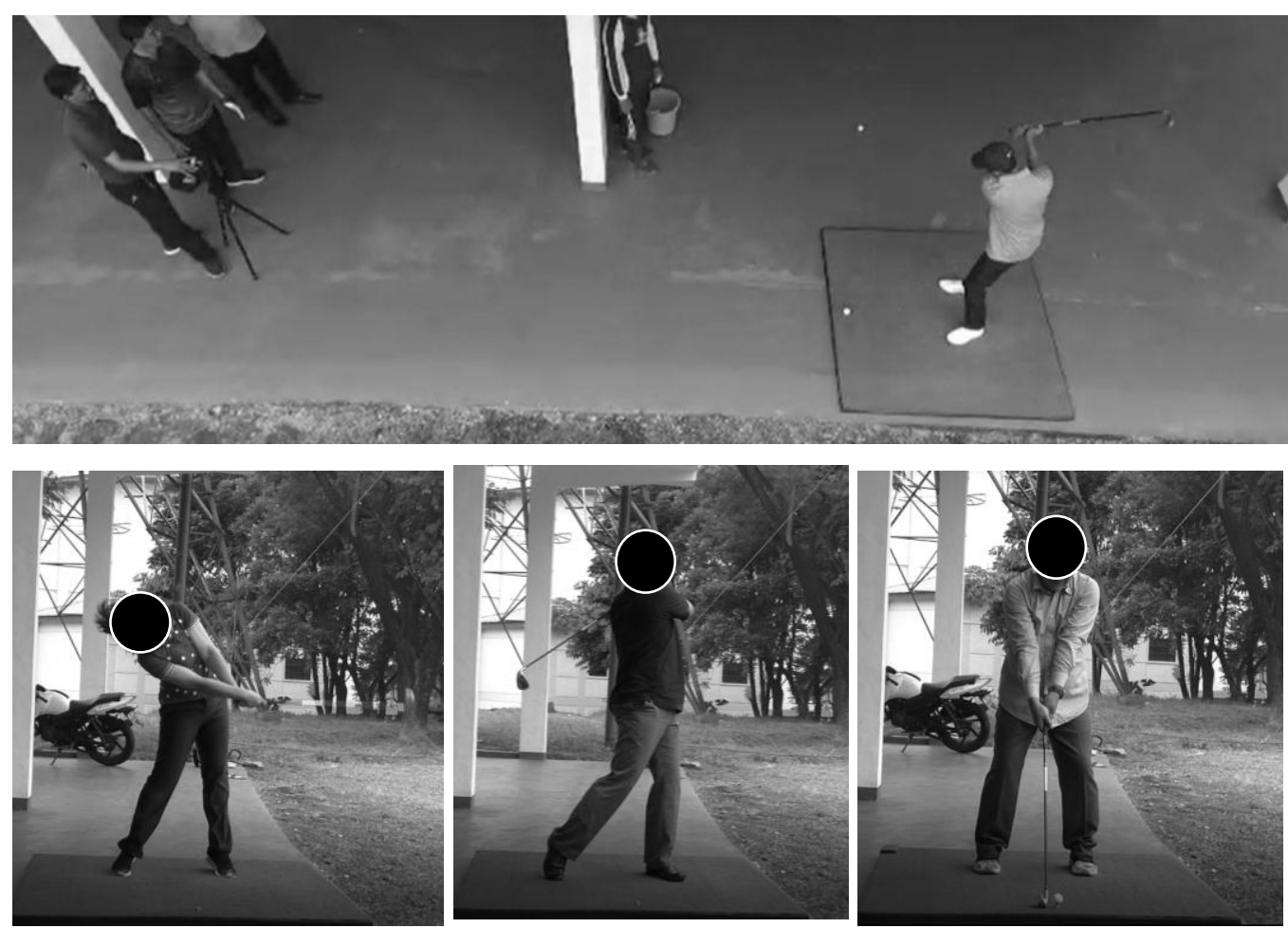

Gambar 2. Proses Pengambilan data di Golf Driving Range FPOK UPI

Metode yang digunakan dalam penelitian ini adalah metode deskriptif kuantitatif. Sedangkan teknik analisis data dalam penelitian ini dengan menggunakan pendekatan analisis uji perbedaan rata-rata dengan melakukan pengujian prasyarat uji normalitas dan homogenitas. Instrumen yang akan digunakan dalam penelitian ini adalah 3 buah Panasonic Handycam HC-V100 Full HD, Satu Unit High Speed Camera (Phantom USA), Satu Set Kalibrasi 2-3 dimensi, Frame DIAZ IV 3D Motion software analysis dan Radar Speed Gun. 


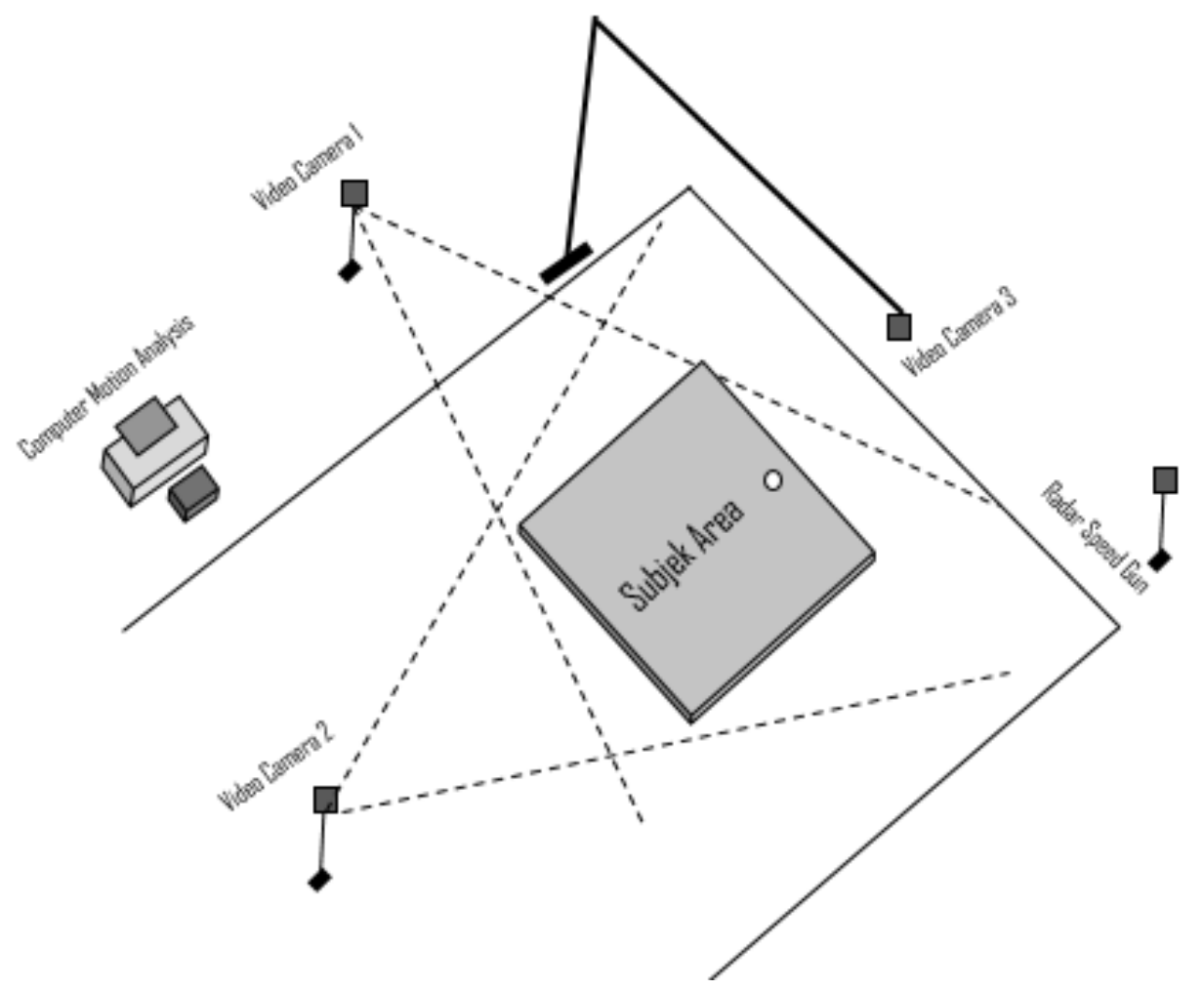

Gambar 3. Skematika pengabilan data lapangan

Adapun skematik pengambilan data dalam penelitian ini yaitu untuk mengukur kecepatan bola menggunakan sebuah Speed Radar Gun yang dipasang di depan area pemukul dengan satuan km/jam. Sedangkan analisis gerak rangkaian gerak kinematika dilakukan melalui rekaman video slow motion system dengan menggunakan tiga buah handycam yang diletakkan di bagian tepi, belakang dan di atas permukaan posisi atlet dengan jarak masing-masing sekitar 3 meter dari subject area. Hasil data rekaman video dianalisis menggunakan pendekatan 2 dimensi dengan menggunakan Frame DIAZ IV software motion analysis. Pengolahan data dari aplikasi ditransfer dalam bentuk format file excel dalam memudahkan proses pengolahan analisis data. 

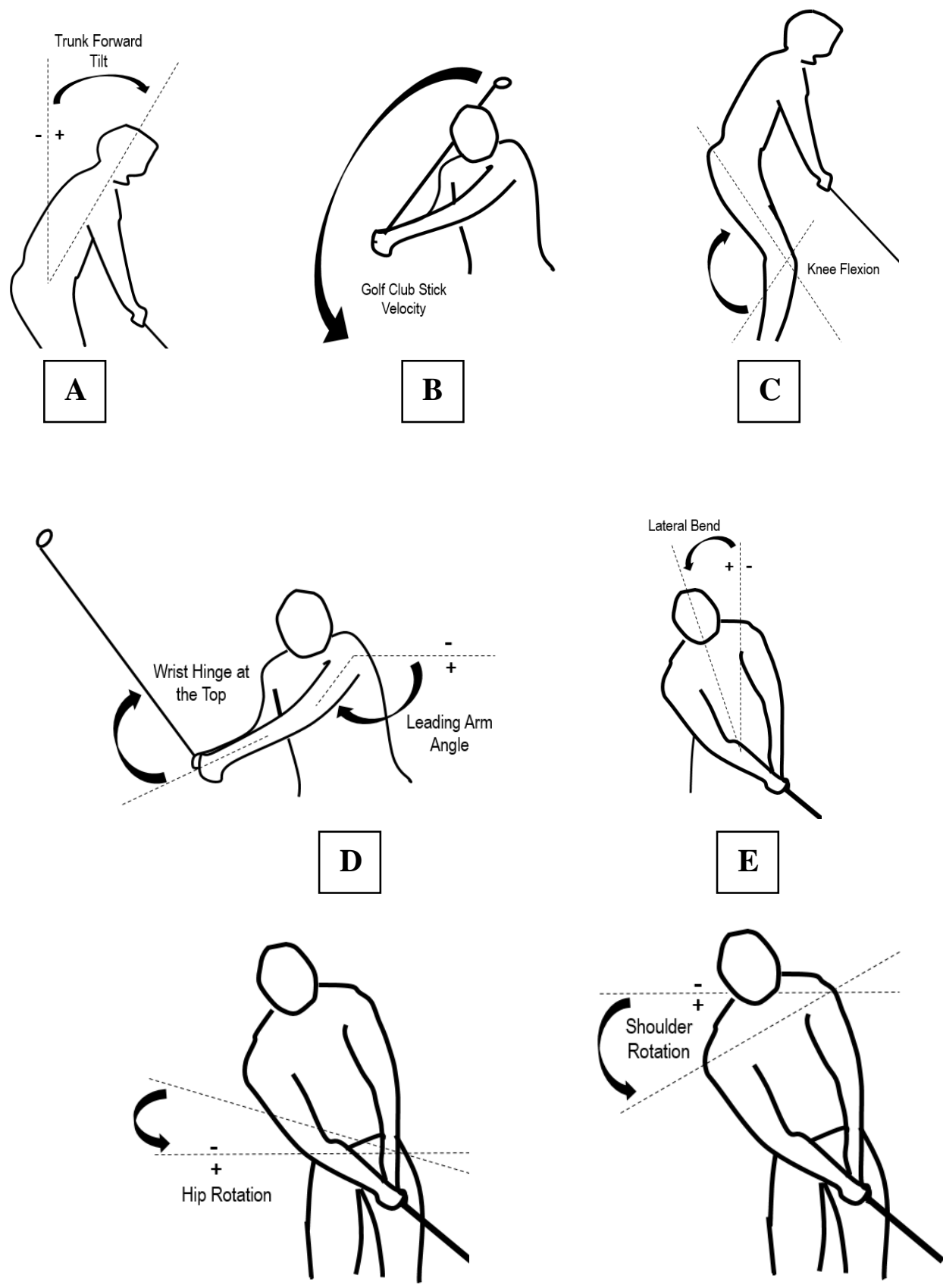

\section{F}

G

Gambar 4. Indikator kinematika analisis; $A$. Trunk forword tilt B. Club stick velocity $C$. Knee Flexion $D$. Wrist hinge at the top and leading arm angle $E$. Lateral band F. Hip rotation $G$. Shoulder rotation.

Dalam memudahkan proses pengolahan analisis maka ditentukan indikator kinematika data yang dianalisis yaitu trunk forword tilt, club stick velocity, knee flexion, wrist hinge at the top, leading arm angle, lateral 
band, hip rotation dan shoulder rotation sesuai gambar 4. Pada proses pengambilan data atlet melakukan pemanasan umum sekitar 10 menit. Kemudian dilanjutkan dengan drive long ball sebanyak 10 kali dengan hasil terbaik dicatat sebagai dokumen.

\section{HASIL DAN PEMBAHASAN}

Tabel 1. Rata-Rata Kecepatan Bola Hasil Pukulan Maximal Drive Long

\begin{tabular}{ccc}
\hline \multirow{2}{*}{ Sampel } & \multicolumn{2}{c}{ Kecepatan Bola $(\mathbf{m} / \mathbf{s})$} \\
\cline { 2 - 3 } & Rata-Rata & Standard Deviasi \\
\hline 1 & 68 & 0.9 \\
2 & 69 & 1.1 \\
3 & 75 & 1.4 \\
4 & 79 & 1.2 \\
5 & 115 & 0.8 \\
6 & 122 & 0.9 \\
\hline
\end{tabular}

Tabel 1 menunjukkan hasil rata-rata kecepatan bola hasil pukulan drive long swing sebanyak 10 kali percobaan. Hasil rata-rata kecepatan bola dari kelompok skilled golfer adalah $118.5 \pm 0.3 \mathrm{~m} / \mathrm{s}$, sedangkan untuk kelompok unskilled golfer kecepatan bola mencapai rata-rata $72.8 \pm$ $1.8 \mathrm{~m} / \mathrm{s}$

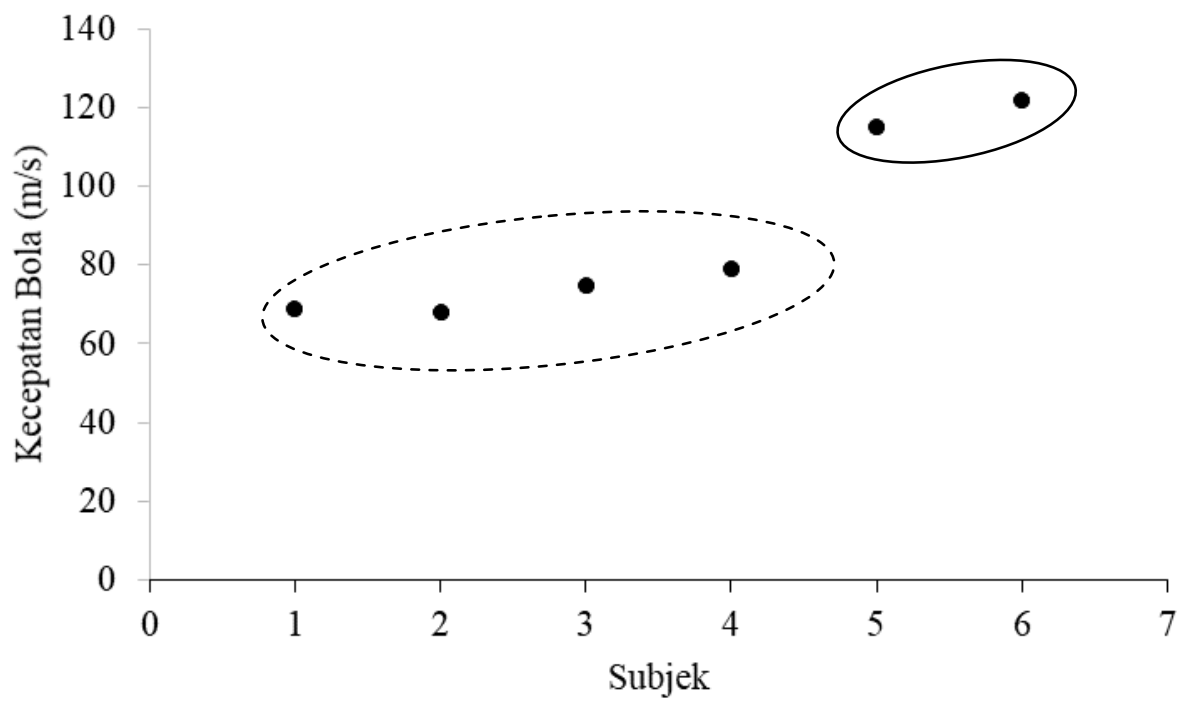

Gambar 5. Keterhubungan antara Hasil Kecepatan Bola dengan Level Golfer

Pada gambar 5 memperlihatkan hasil perbedaan yang signifikan dari hasil kecepatan bola pada saat drive long swing antara skilled dan SPORTIF, 5 (1) 2019 | 41-54 
unskilled dengan rata-rata masing-masing mencapai $118.5 \mathrm{~m} / \mathrm{s}$ dan 72.8 $\mathrm{m} / \mathrm{s} \quad(\mathrm{t}=0.004)$. Hasil dari perbedaan kecepatan bola tersebut dihubungkan dengan rangkaian mekanika gerak kinematika indikator analisis yang dijelaskan pada tabel 2 .

Tabel 2. Hasil Kinematika Indikator Analisis antara Skilled dan Unskilled Golfer

Kinematika Variabel Rata-Rata dan Std.Dev

\begin{tabular}{lcc}
\cline { 2 - 3 } \multicolumn{1}{c}{ Indikator } & Skilled & Unskilled \\
\hline Trunk Forword Tilt (deg) & $33 \pm 0.4$ & $39 \pm 0.8$ \\
Club Speed at Impact (sec)* & $0.54 \pm 0.9^{*}$ & $0.72 \pm 1.2$ \\
Backswing Movement Time (sec) & $2.14 \pm 0.7$ & $2.21 \pm 1.2$ \\
Maximal Knee Flexion (deg) & $19 \pm 0.2$ & $28 \pm 0.4$ \\
Wrist Hinge at the Top (deg) & $27 \pm 0.4$ & $29 \pm 0.9$ \\
Leading Arm Angle (deg) & $210 \pm 0.6$ & $196 \pm 1.8$ \\
Lateral Band at Impact Ball (deg) & $38 \pm 0.2^{*}$ & $12 \pm 0.6$ \\
Hip Rotation at the Top (deg) & $35 \pm 0.6$ & $27 \pm 1.0$ \\
Shoulder Rotation (deg/sec) & $241 \pm 0.4^{*}$ & $198 \pm 1.1$ \\
Flexion at Elbow left Arm (deg)* & $22 \pm 0.8^{*}$ & $4 \pm 0.2$
\end{tabular}

${ }^{*}$ terdapat perbedaan yang signifikan pada taraf $\alpha=0.05$

Hasil perbedaan yang signifikan dari mekanika rangkaian gerak kinematika pada saat drive long swing antara skilled dan unskilled golfer ditunjukkan pada tabel 2. Dari sepuluh indikator kinematika variabel yang dianalisis, terdapat empat indikator yang menunjukkan hasil perbedaan yang signfikan pada taraf alpha 0.05 antara lain club speed at impact $(\mathrm{t}$ $=0.007)$, lateral band after impact ball $(\mathrm{t}=0.006)$, shoulder rotation $(\mathrm{t}=$ 0.005) dan flexion at elbow joint arm non dominant $(\mathrm{t}=0.003)$.

Salah satu faktor pengaruh perubahaan mekanika gerak yang terjadi signifikan pada saat drive long swing terhadap kecepatan bola adalah pada fase backswing dari club stick speed sampai dengan impact ball $(\mathrm{t}=0.007)$ yang mencapai rata-rata $0.51 \pm 0.9$ sec untuk skilled dan $0.72 \pm 1.2$ unskilled golfers. Kemudian tabel 2 menunjukkan data perbedaan yang signifikan pada kecepatan sendi bahu $(t=0.005)$ dengan 
nilai rata-rata $241 \pm 0.4 \mathrm{deg} / \mathrm{s}$ untuk skilled dan $0.72 \pm 1.2 \mathrm{deg} / \mathrm{s}$ unskilled golfers.

Perbedaan kecepatan bola tersebut disebabkan oleh kecepatan shoulder rotation dan leading arm angle yang maksimal. Menurut hasil penelitian Egret, Nicolle, Dujardin, Weber, \& Chollet (2006) pada atlet profesional durasi waktu dari posisi awal persiapan sampai dengan maksimal backswing mencapai rata-rata kurang dari satu detik $(0.82 \mathrm{sec})$. sedangkan dari posisi maksimal backswing menuju pergerakan fase downswing sampai dengan impact mencapai rata-rata $0.23 \mathrm{sec}$ (Kong, Forrester, Wallace, Roberts, \& Smith, 2015). Kecepatan dari sendi panggul dan torso menghasilkan kontribusi $10 \%$ dari total kecepatan linier pada fase downswing untuk atlet profesional (Sim \& Kim, 2010). Pada ketinggian backswing sikut lengan kanan dibengkokkan (abduction at elbow joint) mencapai kira-kira $75^{\circ}$ sampai dengan $90^{\circ}$. Pada fase downswing, perbandingan perbedaan yang signifikan dari rata-rata durasi waktu yang dicapai antara atlet profesional $(0.23 \mathrm{sec})$ dengan atlet tingkat universitas $(0.54 \mathrm{sec})$.

Selanjutnya, terdapat perbedaan yang signifikan pada saat fase backswing ketika lengan sebelah kiri mengayun ke belakang dengan sendi sikut lengan kiri dibengkokan sekitar $22^{\circ}$ pada kelompok unskilled golfer $(\mathrm{t}=0.003)$. Padahal menurut penelitian Gryc, Zahalka, Maly, Mala, \& Hrasky (2015) mengatakan bahwa lengan kiri harus tegak lurus sejajar dengan dengan arah club stik. Hal ini sejalan dengan hasil temuan pada kelompok skilled golfer dimana lengan tegak lurus mencapai rata-rata $4^{\circ}$.

Pada fase follow through atau gerakan lanjutan posisi togok bergerak ke arah lateral yang akan mempengaruhi arah sasaran dan berkontribusi terhadap kecepatan bola (Kwon et al., 2015). Hasil dari penelitian ini juga menunjukan bahwa posisi lateral band after at impact ball sangat berpengaruh signifikan terhadap kecepatan bola $(\mathrm{t}=0.006)$ dengan rata-rata $38 \pm 0.2$ deg untuk kelompok skilled dan $12 \pm 0.6$ deg pada kelompok unskilled golfer. 
Agus Rusdiana, Hadi Sartono, Dede Rohmat Nurjaya, dan Angga M. Syahid

Analisis perbedaan long drive swing mechanical movement terhadap ball velocity berbasis

pendekatan kinematics analysis antara skill dan unskill golf player

\section{KESIMPULAN DAN SARAN}

\section{Kesimpulan}

Harmonisasi rangkaian gerak dari mulai tubuh bagian bawah sampai dengan ayunan stik merupakan kunci keberhasilan teknik long drive swing dalam menghasilkan kecepatan bola maksimal. Perputaran kecepatan sendi panggul sebagai awalan pada downswing yang dilanjutkan dengan kecepatan rotasi sendi bahu merupakan karakteristik gerak atlet professional. Pada saat gerakan lanjutan setalah terjadi perkenaan bola posisi togok lateral merupakan variabel indikator yang signifikan dalam menentukan arah sasaran dan berkontribusi terhadap laju kecepatan bola.

\section{Saran}

Hasil dari penelitian ini dapat ditindaklanjuti berupa saran sebagai berikut:

1. Kajian dari penelitian ini perlu dikembangkan dengan sampel penelitian kepada elit atlet.

2. Analisis indikator variabel dalam penelitian ini hanya terbatas pada kajian kinematika, maka perlu dilanjutkan lebih mendalam pada kajian kinetika.

3. Analisis mekanika gerak drive long swing golf ini menggunakan pendekatan 2 dimensi dengan view gerak sampel yang terbatas, maka perlu dilakukan analisis lebih mendalam dengan pendekatan 3 dimensional.

\section{DAFTAR PUSTAKA}

Bourgain, M., Hybois, S., Thoreux, P., Rouillon, O., Rouch, P., \& Sauret, C. (2018). Effect of shoulder model complexity in upper-body kinematics analysis of the golf swing. Journal of Biomechanics, 75, 154-158. https://doi.org/10.1016/j.jbiomech.2018.04.025

Egret, C. I., Nicolle, B., Dujardin, F. H., Weber, J., \& Chollet, D. (2006). Kinematic analysis of the golf swing in men and women experienced golfers. International Journal of Sports Medicine, 27(6), 463-467. https://doi.org/10.1055/s-2005-865818 
Evans, K., \& Tuttle, N. (2015). Improving performance in golf: Current research and implications from a clinical perspective. Brazilian Journal of Physical Therapy, 19(5), 381-389. https://doi.org/10.1590/bjptrbf.2014.0122

Ferdinands, R. E. D., Kersting, U. G., \& Marshall, R. N. (2013). A twentysegment kinematics and kinetics model for analysing golf swing mechanics. Sports Technology, 6(4), 184-201. https://doi.org/10.1080/19346182.2013.854799

Gryc, T., Zahalka, F., Maly, T., Mala, L., \& Hrasky, P. (2015). Movement's analysis and weight transfer during the golf swing. Journal of Physical Education and Sport, 15(4), 781-787. https://doi.org/10.7752/jpes.2015.04119

Joyce, C., Burnett, A., Cochrane, J., \& Ball, K. (2013). Three-dimensional trunk kinematics in golf: Between-club differences and relationships to clubhead speed. Sports Biomechanics, 12(2), 108-120. https://doi.org/10.1080/14763141.2012.728244

Keogh, J. W. L., \& Hume, P. A. (2012). Evidence for biomechanics and motor learning research improving golf performance. Sports Biomechanics, 11(2), 288-309. https://doi.org/10.1080/14763141.2012.671354

Kong, P. W., Forrester, S., Wallace, E., Roberts, J., \& Smith, A. (2015). Golf Coaches' Perceptions of Key Technical Swing Parameters Compared to Biomechanical Literature. International Journal of Sports Science \& Coaching, 10(4), 739-755. https://doi.org/10.1260/17479541.10.4.739

Kwon, M. S., Kim, S., Lim, Y.-T., Park, S. J., \& Sung, D. J. (2015). Effects of core and non-dominant arm strength training on drive distance in elite golfers. Journal of Sport and Health Science, 5(2), 219-225. https://doi.org/10.1016/j.jshs.2014.12.006

Langdown, B. L., Bridge, M., \& Li, F. X. (2012). Movement variability in the golf swing. Sports Biomechanics, 11(2), 273-287. https://doi.org/10.1080/14763141.2011.650187

Meister, D. W., Butler, E. E., Rose, J., Rogers, A. P., Ray, C. J., Zhao, B., \& Ladd, A. L. (2016). Rotational Biomechanics of the Elite Golf Swing: Benchmarks for Amateurs. Journal of Applied Biomechanics, 27(3), 242-251. https://doi.org/10.1123/jab.27.3.242

Morrison, A., McGrath, D., \& Wallace, E. S. (2018). Analysis of the delivery plane in the golf swing using principal components. Proceedings of the Institution of Mechanical Engineers, Part P: Journal of Sports Engineering and Technology, 232(4), 295-304. https://doi.org/10.1177/1754337117751729 
Mun, F., Suh, S. W., Park, H. J., \& Choi, A. (2015). Kinematic relationship between rotation of lumbar spine and hip joints during golf swing in professional golfers. BioMedical Engineering Online, 14(1), 1-10. https://doi.org/10.1186/s12938-015-0041-5

Nesbit, S. M. (2007). Development of a full-body biomechanical model of the golf swing. International Journal of Modelling and Simulation, 27(4), 392-404. https://doi.org/10.1080/02286203.2007.11442442

Sato, K., Kenny, I. C., \& Dale, R. B. (2013). Current golf performance literature and application to training. Journal of Trainology, 2, 23-32.

Sim, M., \& Kim, J. U. (2010). Differences between experts and novices in kinematics and accuracy of golf putting. Human Movement Science, 29(6), 932-946. https://doi.org/10.1016/j.humov.2010.07.014

Tinmark, F., Hellström, J., Halvorsen, K., \& Thorstensson, A. (2010). Elite golfers' kinematic sequence in full-swing and partialswing shots. Sports Biomechanics, 9(4), 236-244. https://doi.org/10.1080/14763141.2010.535842

Vena, A., Budney, D., Forest, T., \& Carey, J. P. (2011). Three-dimensional kinematic analysis of the golf swing using instantaneous screw axis theory, part 1: Methodology and verification. Sports Engineering, 13(3), 105-123. https://doi.org/10.1007/s12283-010-0058-8 